\title{
Spectrum of Thyroid Abnormalities among Pregnant Women in Basrah
}

\author{
Ammar Mohammed Saeed Almomin ${ }^{1}$ and Abbas Ali Mansour ${ }^{2 *}$ \\ ${ }^{1}$ Faiha Specialized Diabetes, Endocrine, and Metabolism Center (FDEMC), Iraq \\ ${ }^{2}$ Department of Medicine, University of Basrah, Iraq
}

Submission: January 22, 2019; Published: March 11, 2019

*Corresponding author: Abbas Ali Mansour, Diabetes, Endocrine and Metabolism Division, Department of Medicine, College of Medicine, University of Basrah, Hattin post office P.0 Box: 142, Basrah - 61013, Iraq

\begin{abstract}
Background: Thyroid dysfunction is the second most common endocrine disorder in pregnancy coming only after diabetes mellitus.

Objective: to see the spectrum of abnormal thyroid function among apparently healthy pregnant women in Basrah (Southern Iraq).

Patients and methods: This was a cross-sectional study conducted between January 2014 and June 2015 for the screening of thyroid function in pregnant women in Basrah. Initially, we enrolled 893 pregnant women, and after applying exclusion criteria reduced to 628 pregnant women, they are divided into two groups according to anti-thyroid peroxidase (anti-TPO) antibodies status. Pregnant women sent for thyroid stimulating hormone (TSH), free thyroxine (FT4), and anti-TPO antibody tests. The samples were collected from private and public sectors in Basrah city (Southern Iraq).

Results: thyroid dysfunction was significantly higher in anti-TPO positive pregnant women, compared to those who were negative $(39.6 \%$ versus $18.4 \%$ respectively). For anti-TPO negative antibody pregnant women, the following results were obtained; isolated hypothyroxinemia $5.4 \%$, isolated hyperthyroxinemia $3.6 \%$, subclinical hypothyroidism $4.2 \%$, clinical hypothyroidism $0.4 \%$, subclinical hyperthyroidism $3.9 \%$, and clinical hyperthyroidism $0.6 \%$. While for anti-TPO positive antibody pregnant women the results were as follow; subclinical hypothyroidism $10.4 \%$, isolated hypothyroxinemia $8.5 \%$, isolated hyperthyroxinemia $5.7 \%$, clinical hypothyroidism $7.5 \%$, subclinical and clinical hyperthyroidism in $4.7 \%$ and $2.8 \%$ respectively.
\end{abstract}

Conclusion: Thyroid dysfunctions are common during pregnancy. Subclinical hypothyroidism and isolated hypothyroxinemia were the two most common thyroid abnormalities seen in pregnant women. Anti-TPO antibodies positivity predict an increase in thyroid diseases especially clinical and subclinical thyroid diseases.

Keywords: Pregnancy; Thyroid dysfunction; Subclinical hypothyroidism; Subclinical hyperthyroidism; Isolated hypothyroxinemia; Thyroid peroxidase antibodies

\section{Introduction}

Thyroid dysfunction is the second most common endocrine disorder after diabetes mellitus, affecting women in fertile age period [1]. Societies living in different geographical areas of the world may have different thyroid function tests parameters [2]. Thyroid dysfunction during pregnancy is relatively high mostly occurs in subclinical form (about 10\%), while overt thyroid dysfunction occurs in 2-3\% of pregnancies [3]. Some normal physiological changes during pregnancy alter thyroid function test parameters, which should be taken into consideration. The increase in estrogens induces an increase in thyroxine-binding globulin (TBG) which increases the total (bound) thyroid hormones, in addition, human chorionic gonadotropin hormone has some thyrotropic activity that induces a slight increase in free thyroxine (FT4) with a peak at the end of the first trimester, and this causes a transient decrease in thyroid stimulating hormone(TSH) [4]. Thus caution should be taken when using non-pregnant reference ranges of FT4 and TSH for pregnant woman and certain standardization required to validate their values [5].

Maintaining normal thyroid function during pregnancy is vital to both mother and baby, where hypothyroxinemia was associated with worse metabolic parameters with increased obesity, triglycerides and insulin resistance in the mother [6] while hypertension was associated with both 
hypo and hyperthyroidism [7]. Moreover, the fetus depends on mother thyroid hormones for his brain development in the first and second trimesters [8]. Pregnant woman with subclinical hypothyroidism in addition to hyperthyroidism and hypothyroidism have increased the risk of intrauterine growth retardation (IUGR) [9]. Overt hypothyroidism during pregnancy was also associated with several complications including increased risk of caesarian section delivery $[10,11]$. The adverse effects of subclinical hypothyroidism ( $\mathrm{SCH}$ ) accompanied with positive anti-thyroid peroxidase(anti-TPO) antibodies, or overt hypothyroidism on pregnancy outcome are well known. However, there is controversy over the adverse impact of SCH without autoimmunity on pregnancy outcomes [12].

Although some researchers reported no significant increase of placental abruption, preterm labor and low birth weight in pregnancy complicated by subclinical hyperthyroidism in comparison with euthyroid ones, [13] others reported that thyrotoxicosis is associated with a risk of spontaneous abortion, congestive heart failure, thyrotoxic storm, preeclampsia, preterm delivery, low birth weight, and stillbirth [14]. The objectives of this study were to see the spectrum of abnormal thyroid function among apparently healthy pregnant women in Basrah (Southern Iraq).

\section{Methods}

\section{Setting}

This study was a cross-sectional study included pregnant women selected from people attending Primary Health Centers (PHC), hospital outpatient clinic, and private gynecologic clinics in the city of Basrah (Southern of Iraq) and conducted between January 2014 and June 2015 for the screening of thyroid function in pregnant women in Basrah to established trimester specific normal thyroid values and detect thyroid dysfunctions among pregnant women in Basrah by the Faiha Specialized Diabetes Endocrine and Metabolism Center(FDEMC). The first part of the study was published previously [15]. Written informed consent was taken from all women to participate in this study, and the ethical committee of the College of Medicine in Basrah University approved the study.

Inclusion criteria: subject inclusion criteria were healthy pregnant women with uncomplicated single intrauterine gestation who gave written informed consent to participated in this study.

Exclusion criteria: any patient with a history of hyperemesis gravidarum, use of medication known to affect thyroid function, thyroid surgery, any significant acute or chronic diseases were excluded from the study.

From the total number of 893 participants, 31 excluded by history and 234 have their samples lost during processing; the remaining 628 women have accomplished sampling for TSH,
FT4, and anti-TPO antibodies. (Figure 1) In this study, we use our local values of trimester-specific thyroid function in Basrah. TSH value between $0.04-3.77 \mu \mathrm{IU} / \mathrm{mL}$ considered normal for women in the first trimester, $0.30-3.21 \mu \mathrm{IU} / \mathrm{mL}$ for the second trimester and $0.60-4.5 \mu \mathrm{IU} / \mathrm{mL}$ for the third trimester. While FT4 value between $0.8-1.53 \mathrm{ng} / \mathrm{dL}$ considered normal for the first trimester, $0.7-1.2 \mathrm{ng} / \mathrm{dL}$ considered normal for both second and third trimesters.

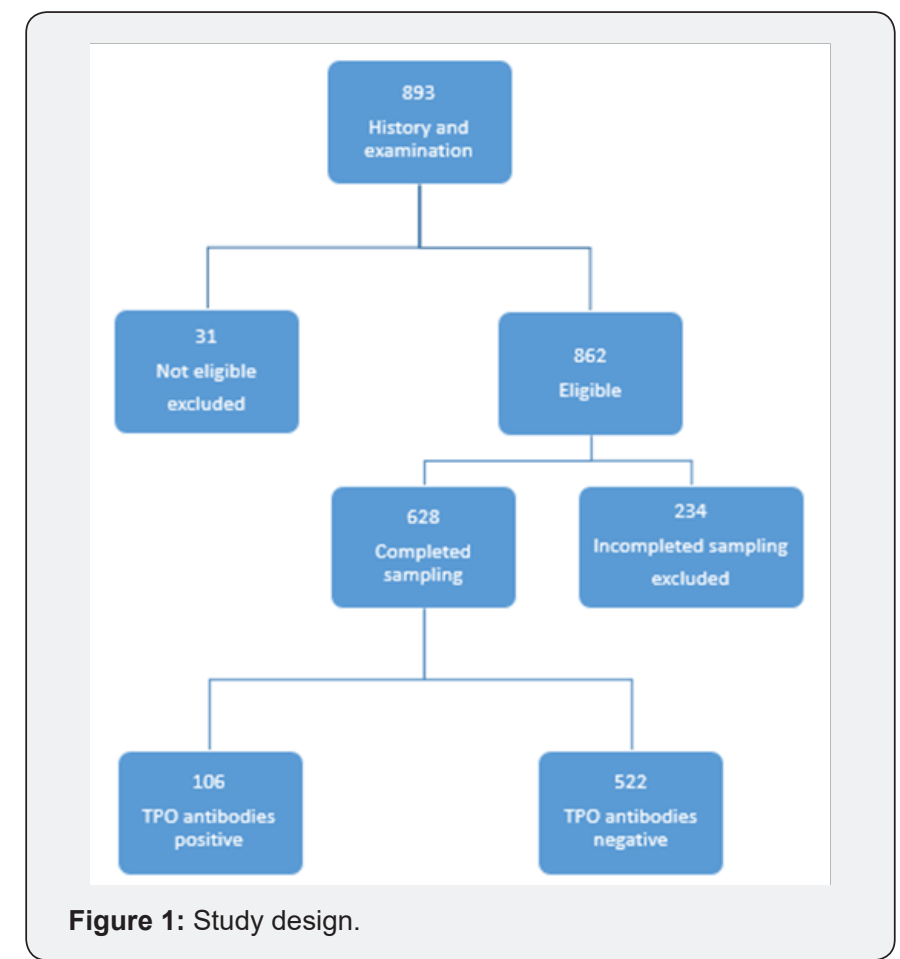

Pregnant women with high TSH and normal FT4 were considered as having subclinical hypothyroidism. Those with high TSH and low FT4 were considered to have overt hypothyroidism. Subclinical hyperthyroidism used in those with low TSH and normal FT4 and overt hyperthyroidism was diagnosed in those with low TSH and high FT4. Isolated hyper and hypothyroxinemia considered respectively for elevated and reduced FT4 despite normal TSH. Positive anti-TPO antibodies were considered if the level is $34 \mathrm{IU} / \mathrm{mL}$ or above. Each patient included in the study sampled for a once during pregnancy and never been tested again throughout the same pregnancy.

\section{Biochemical Tests}

All was done by an electrochemiluminescence (ECL) technique using commercially available kits from Roche Diagnostics (Germany) with cobas e 411 analyzer. The analysis was done in FDEMC laboratory. The intra-assay coefficients of variations were as follows: TSH $0.1-4 \mu \mathrm{U} / \mathrm{mL}(<5 \% \mathrm{CV})$, FT4 $25-$ $100 \mathrm{pmol} / \mathrm{L}(<3 \% \mathrm{CV})$, and anti-TPO antibodies $>40 \mathrm{IU} / \mathrm{ML}(<7 \%$ $\mathrm{CV}$ ). The measuring range and normal values were mentioned before [15]. 


\section{Journal of Endocrinology and Thyroid Research}

\section{Statistical Analysis}

For statistics, all data were computed and analyzed using SPSS, (version 15.0).

\section{Results}

The mean age was approximately $28 \pm 7.2$ years. The number of women according to the trimesters were 155 (24.6\%), 283 $(45.1 \%)$ and $190(30.3 \%)$ for the first trimester, second and third trimesters respectively. From a total number of 628 women, the anti-TPO antibody was positive in 106 (16.9\%). While the remaining $522(83.1 \%)$ were negative. In negative anti-TPO antibodies pregnant women, 426(81.6\%) were having normal thyroid function. This means that $96(18.4 \%)$ were having some abnormality in thyroid function. Isolated hypothyroxinemia was the most prevalent thyroid disorder seen in 28(5.4\%). While Subclinical hypothyroidism and hyperthyroidism were observed in $22(4.2 \%)$ and $20(3.9 \%)$ respectively (Table 1) (Figure 2).

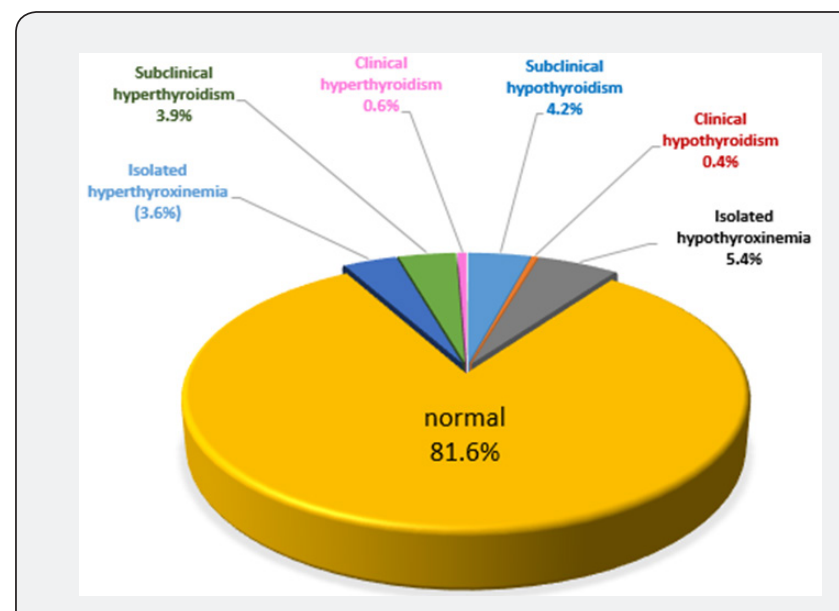

Figure 2: Spectrum of thyroid disease among pregnant women with negative anti-TPO antibodies.

Table 1: Spectrum of thyroid disease among 522 pregnant women with negative anti-TPO antibodies.

\begin{tabular}{|c|c|}
\hline Thyroid disease type & No. (\%) \\
\hline Normal thyroid function & $426(81.6)$ \\
\hline $\begin{array}{c}\text { Isolated low FT4(Isolated hypo- } \\
\text { thyroxinemia) }\end{array}$ & $28(5.4)$ \\
\hline Subclinical hypothyroidism & $22(4.2)$ \\
\hline Subclinical hyperthyroidism & $20(3.9)$ \\
\hline $\begin{array}{c}\text { Isolated high FT4(Isolated hyper- } \\
\text { thyroxinemia) }\end{array}$ & $19(3.6)$ \\
\hline Clinical hyperthyroidism & $3(0.6)$ \\
\hline Clinical hypothyroidism & $2(0.4)$ \\
\hline
\end{tabular}

Of 106 patients with anti-TPO antibodies women, 64 (60.4\%) were having normal thyroid function.For pregnant women with positive anti-TPO antibodies, subclinical hypothyroidism was the most frequent abnormality, seen in $11(10.4 \%)$ followed by isolated hypothyroxinemia observed in 9 (8.5\%) of pregnant women (Table 2) (Figure 3). Clinical hypothyroidism and isolated high FT4 (isolated hyperthyroxinemia) were seen in 8 (7.5\%) and $6(5.7 \%)$ respectively. Subclinical and clinical hyperthyroidism was observed in $5(4.7 \%)$ and $3(2.8 \%)$ pregnant women respectively. Collectively thyroid dysfunction was significantly higher in anti-TPO positive pregnant women, compared to those who were negative (39.6\% versus $18.4 \%$ respectively) (Table 3 ).

Table 2: Spectrum of thyroid disease among 106 pregnant women with positive anti-TPO antibodies.

\begin{tabular}{|c|c|}
\hline Thyroid disease type & No. (\%) \\
\hline Normal thyroid function & $64(60.4 \%)$ \\
\hline Subclinical hypothyroidism & $11(10.4 \%)$ \\
\hline $\begin{array}{c}\text { Isolated low FT4(Isolated hypothy- } \\
\text { roxinemia) }\end{array}$ & $9(8.5 \%)$ \\
\hline $\begin{array}{c}\text { Clinical hypothyroidism } \\
\text { thyroxinemia) }\end{array}$ & $8(7.5 \%)$ \\
\hline Sulated high FT4(Isolated hyper- & $6(5.7 \%)$ \\
\hline Clinical hyperthyroidism & $5(4.7 \%)$ \\
\hline Total & $3(2.8 \%)$ \\
\hline
\end{tabular}

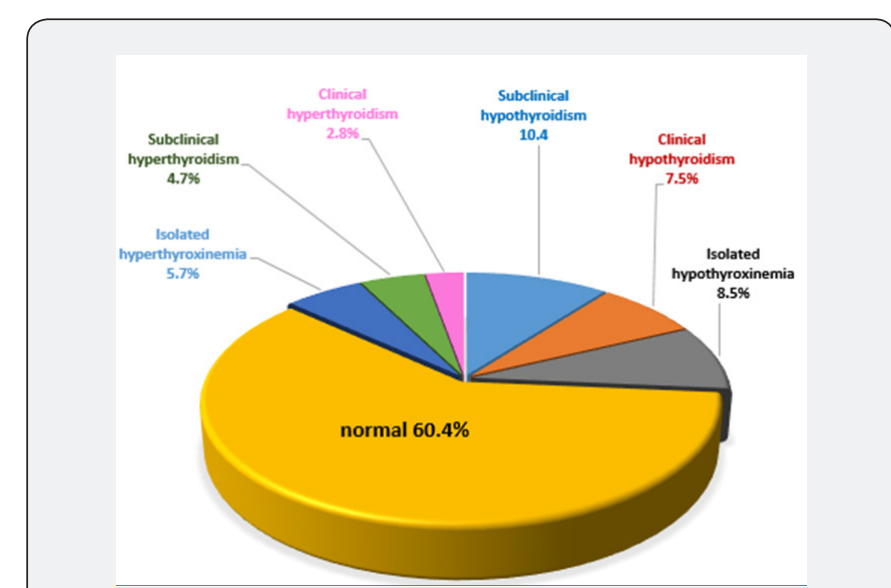

Figure 3: Spectrum of thyroid disease among pregnant women with positive anti-TPO antibodies.

Table 3: Total percentage of patients having thyroid disease according to anti-TPO antibodies state.

\begin{tabular}{|c|c|c|c|c|}
\hline & \multicolumn{3}{|c|}{ Thyroid dysfunction } \\
\cline { 1 - 4 } $\begin{array}{c}\text { Anti-TPO } \\
\text { antibodies }\end{array}$ & $\begin{array}{c}\text { Present No. } \\
\text { (\%) }\end{array}$ & $\begin{array}{c}\text { Absent No. } \\
\text { (\%) }\end{array}$ & Total & \\
\cline { 1 - 4 } Negative & $96(18.4 \%)$ & $426(81.6 \%)$ & $522(100 \%)$ & $\begin{array}{c}\text { p-value } \\
<0.001\end{array}$ \\
\cline { 1 - 3 } Positive & $42(39.6 \%)$ & $64(60.4 \%)$ & $106(100 \%)$ & \\
\hline
\end{tabular}

\section{Discussion}

Subclinical hypothyroidism is the most common thyroid dysfunction during pregnancy [16]. In this study subclinical hypothyroidism in pregnant women, was lower to what has been seen in India and Congo (6.47\% and $12 \%$ respectively) [10,17]. In India, they use the CLIA chemiluminescence immunoassay technique, but they use laboratory reference value for TSH 0.5- $5 \mu \mathrm{IU} / \mathrm{mL}$ to differentiate clinical thyroid categories. They 
did not measure FT4 routinely, but they use it selectively. In the Congo study the difference might be because they used median results rather than the mean as we did, in addition, they did use colorimetric method while we use electrochemiluminescent one, they did use a combination of American Thyroid Association (ATA) guidelines with manufacturer reference values as a cut limit to diagnose normal and abnormal thyroid functions. Of those diagnosed as having subclinical hypothyroidism one half were found to be positive anti-TPO antibodies. This was higher to what has been seen in Bengal-India which report about $34 \%$. On the other hand, the Bengal study reported subclinical hypothyroidism in $32.9 \%$ of pregnant women which is significantly higher to what has been seen in our study, probably because they use a cut-off equal to $2.5 \mu \mathrm{IU} / \mathrm{mL}$ for TSH [18].

In our study, clinical hypothyroidism was found in about $0.4 \%$ of negative anti-TPO antibodies, while in India it is about $13.13 \%$ which is significantly higher than in our study [19]. The Indian study was using a TSH cut off equal to $4.5 \mu \mathrm{IU} / \mathrm{mL}$ as the upper limit of normal. Our local study considers TSH of $3.7 \mu \mathrm{IU} /$ $\mathrm{mL}, 3.2 \mu \mathrm{IU} / \mathrm{mL}$, and $4.5 \mu \mathrm{IU} / \mathrm{mL}$ as the upper limit of normal for each trimester respectively. This may explain the difference between our prevalence values. While a Mexican study gives nearer values to our results of about $1.11 \%$ [20].

Subclinical hyperthyroidism with negative anti-TPO antibodies was found in about $3.9 \%$ of our studied population; this was more than double of Casey and his colleague's results [12]. The difference from Casey study is that they use weekly gestational age reference range for TSH, but the FT4 value was not adjusted for gestational age. While our study uses trimester specific values for both TSH and FT4.

In general hyperthyroidism during pregnancy was less frequently seen than hypothyroidism [21]. The prevalence of hyperthyroidism during pregnancy is about $0.2 \%$ in an American study [22] while in the current study in Iraq the prevalence of clinical hyperthyroidism is higher $0.6 \%$. Overt hyperthyroidism during pregnancy if being due to Graves' disease could result in fetal thyroid dysfunction [23]. Isolated hypothyroxinemia may be defined by some authors as normal TSH and FT4 below the reference range [24], where others may define isolated hypothyroxinemia as a normal level of TSH with FT4 below the 2.5th, 5th, or 10th percentile of normal pregnant women $[25,26]$. Iron deficiency may also precipitate a state of hypothyroxinemia [27]. Isolated hypothyroxinemia was seen in about $8.5 \%$ of positive anti-TPO antibodies pregnant women. Although controversial some studies showed that isolated hypothyroxinemia in pregnancy is associated with worse metabolic parameters with increased obesity, hyperglycemia, hypertriglyceridemia, and increased insulin resistance as compared with euthyroid and subclinical hypothyroid pregnant women.

As compared to the Exeter family study of childhood health results that showed the incidence of isolated hypothyroxinemia of about $8.6 \%$ [28] which is higher than in our study. The isolated hypothyroxinemia was considered if TSH is normal per trimester, but FT4 was below the 10th centile $(0.81 \mathrm{ng} /$ $\mathrm{dL}$ ). Exeter study was taking investigation sample in the 28 weeks of gestation, while we took it at different times during pregnancy. More significant sample size and longer duration of the study about five years for Exeter, as compared to 1.5 years and a smaller sample size for our study. Both studies used electro chemiluminescent immunoassay, (Roche) analyzer. The same definition of the isolated hypothyroxinemia but different cut levels were used for each study. We used local reference values, while Exeter used manufacturer value for FT4 and a cut value of $3 \mu \mathrm{IU} / \mathrm{mL}$ for TSH.

Isolated hyperthyroxinemia was seen in a small percentage in our study. Maternal euthyroid hyperthyroxinemia could have beneficial rather than harmful effect, where it may reduce the incidence of preterm delivery in multiparous women as shown by a German study [29]. Generally, in our study anti-TPO positivity confer a higher chance of thyroid dysfunctions. This was in accordance to what have been seen in the PORMETS study from Portugal [30].

\section{Conclusion}

Thyroid dysfunctions are common during pregnancy. Subclinical hypothyroidism and isolated hypothyroxinemia were the two most common thyroid abnormalities seen in pregnant women regardless of anti-TPO antibodies state. Positive antiTPO antibodies predict an increase in the prevalence of thyroid disease especially clinical and subclinical thyroid dysfunctions.

\section{References}

1. Cooper DS, Laurberg P (2013) Hyperthyroidism in pregnancy. Lancet Diabetes Endocrinol 1(3): 238-49.

2. Rajput R, Singh B, Goel V, Verma A, Seth S, et al. (2016) Trimesterspecific reference interval for thyroid hormones during pregnancy at a Tertiary Care Hospital in Haryana, India. Indian J Endocrinol Metab 20(6): 810-815.

3. Azizi F, Delshad H (2014) Thyroid Derangements in Pregnancy. Iranian Journal of Endocrinology and Metabolism 15 (6): 491-508.

4. Fitzpatrick DL, Russell MA (2010) Diagnosis and management of thyroid disease in pregnancy. Obstet Gynecol Clin North Am 37(2): 173-93.

5. De Groot L, Abalovich M, Alexander EK, Amino N, Barbour L, et al. (2012) Management of Thyroid Dysfunction during Pregnancy and Postpartum: an Endocrine Society clinical practice guideline. J Clin Endocrinol Metab 97(8): 2543-65.

6. Knight BA, Shields BM, Hattersley AT, Vaidya B (2016) Maternal hypothyroxinaemia in pregnancy is associated with obesity and adverse maternal metabolic parameters. Eur J Endocrinol 174: 51-57.

7. Fazio S, Palmieri EA, Lombardi G, Biondi B (2004) Effects of thyroid hormone on the cardiovascular system. Recent Prog Horm Res 59: 3150.

8. Calvo RM, Jauniaux E, Gulbis B, Asunción M, Gervy C, et al. (2002) Fetal tissue are exposed to biologically relevant free thyroxine concentrations during early phases of development. J Clin Endocrinol Metab 87(4): 1768-1777. 
9. Saki F, Dabbaghmanesh MH, Ghaemi SZ, Forouhari S, Ranjbar Omrani G, et al. (2014) Thyroid Function in Pregnancy and Its Influences on Maternal and Fetal Outcomes. Int J Endocrinol Metab 12(4): e19378.

10. Sahu MT, Das V, Mittal S, Agarwal A, Sahu M (2010) Overt and subclinical thyroid dysfunction among Indian pregnant women and its effect on maternal and fetal outcome. Arch Gynecol Obstet 281(2): 215-220.

11. Monen L, Pop VJ, Hasaart TH, Wijnen H, Oei SG, et al. (2015) Increased maternal TSH and decreased maternal FT4 are associated with a higher operative delivery rate in low-risk pregnancies: A prospective cohort study. BMC Pregnancy and Child birth 15: 267.

12. Negro R, Formoso G, Mangieri T, Pezzarossa A, Dazzi D, et al. (2006) Levothyroxine treatment in euthyroid pregnant women with autoimmune thyroid disease: effects on obstetrical complications. J Clin Endocrinol Metab 91(7): 2587-2591.

13. Casey BM, Dashe JS, Wells CE, McIntire DD, Leveno KJ, et al. (2006) Subclinical hyperthyroidism and pregnancy outcomes. Obstet Gynecol 107(2 Pt 1): 337-41.

14. Andersen SL, Olsen J, Wu CS, Laurberg P. (2014) Spontaneous abortion, stillbirth and hyperthyroidism: a Danish populationbased study. Eur Thyroid J 3(3): 164-172.

15. Almomin AMS, Mansour AA, Sharief M (2016) Trimester-Specific Reference Intervals of Thyroid Function Testing in Pregnant Women from Basrah, Iraq Using Electrochemiluminescent Immunoassay. Diseases 4(2): 20

16. Okosieme EO, Lazarus JH (2010) Thyroid dysfunction in pregnancy: optimizing fetal and maternal outcomes. Expert Review of Endocrinology and Metabolism 5(4): 521-529.

17. Habimana L, Twite KE, Daumerie C, Wallemacq P, Donnen P, et al. (2014) High Prevalence of Thyroid Dysfunction Among Pregnant Women in Lubumbashi, Democratic Republic of Congo. Thyroid 24(3): 568-575.

18. Mandal RC, Bhar D, Das A, Basunia SR, Kundu SB, et al. (2016) Subclinical hypothyroidism in pregnancy: An emerging problem in Southern West Bengal: A cross-sectional study. J Nat Sci Biol Med 7(1): 80-84.

19. Dhanwal DK, Bajaj S, Rajput R, Subramaniam KA, Chowdhury S, et al. (2016) Prevalence of hypothyroidism in pregnancy: An epidemiological study from 11 cities in 9 states of India. Indian J Endocrinol Metab 20(3): 387-90.
20. López-Muñoz E, Ibarra-Avalos JA, Chan-Verdugo RG, Mateos-Sánchez L, Sánchez-Rodríguez 0 (2016) Prevalence of hypothyroidism during pregnancy in a highly specialised referral centre in Mexico. J Obstet Gynaecol 36(8): 1069-1075.

21. Negro R, Mestman JH (2011) Thyroid disease in pregnancy. Best Practice and Research Clinical Endocrinology and Metabolism. 25: 927-943.

22. American College of Obstetricians and Gynecologists (2015) Practice Bulletin No. 148: thyroid disease in pregnancy. Obstet Gynecol 125(4): 996-1005.

23. Gietka-Czernel M, Dębska M, Kretowicz P, Zgliczyński W, Ołtarzewski M (2014) Hyperthyroidism during pregnancy-the role of measuring maternal TSH receptor antibodies and foetal ultrasound monitoring. Endokrynol Pol 65(4): 259-68.

24. Chan S, Boelaert K (2015) Optimal management of hypothyroidism, hypothyroxinaemia and euthyroid TPO antibody positivity preconception and in pregnancy. Clin Endocrinol (Oxf) 82(3): 313-326.

25. Lazarus J, Brown RS, Daumerie C, Hubalewska-Dydejczyk A, Negro $\mathrm{R}$, et al. (2014) European thyroid association guidelines for the management of subclinical hypothyroidism in pregnancy and in children. European Thyroid Journal. 3(2): 76-94.

26. Díez JJ, Iglesias P, Donnay S (2015) Thyroid dysfunction during pregnancy. Med Clín (Barc) 145(8): 344-349.

27. Yu X, Shan Z, Li C, Mao J, Wang W, et al. (2015) Iron deficiency, an independent risk factor for isolated hypothyroxinemia in pregnant and nonpregnant women of childbearing age in China. Journal of Clinical Endocrinology and Metabolism 100(4): 1594-601.

28. Knight BA, Shields BM, Hattersley AT, Vaidya B (2016) Maternal hypothyroxinaemia in pregnancy is associated with obesity and adverse maternal metabolic parameters. Eur J Endocrinol 174(1): 5157.

29. Torremante P, Kirschner W, Muche R, Flock F (2017) Maternal Euthyroid Hyperthyroxinemia May Reduce Preterm Birth Rate in Multiparous Women. Scientific Research 7(6): 623-638.

30. Raposo L, Martins S, Ferreira D, Guimaraes JT, Santos AC (2018) Metabolic Syndrome, Thyroid Function and Autoimmunity - The PORMETS Study. Endocr Metab Immune Disord Drug Targets 19(1): 75-83.

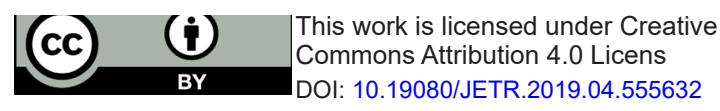

\begin{tabular}{l} 
Your next submission with Juniper Publishers \\
will reach you the below assets \\
- Quality Editorial service \\
- Swift Peer Review \\
- Reprints availability \\
- E-prints Service \\
- Manuscript Podcast for convenient understanding \\
- Global attainment for your research \\
- Manuscript accessibility in different formats \\
( Pdf, E-pub, Full Text, Audio) \\
- Unceasing customer service \\
Track the below URL for one-step submission \\
https://juniperpublishers.com/online-submission.php \\
\hline
\end{tabular}

